\title{
Física no esporte - Parte 1: saltos em esportes coletivos. Uma motivação para o estudo da mecânica através da análise dos movimentos do corpo humano a partir do conceito de centro de massa (Physics in the sport - Part 1: jumps in collective sports. A motivation for the study of mechanics through the analysis of the movements of human body from the concept of center of mass)
}

\author{
Daniel Neves Micha ${ }^{\boxplus, 2,3}$, Mauro Ferreira ${ }^{4}$ \\ ${ }^{1}$ Coordenação da Licenciatura em Física, Centro Federal de Educação Tecnológica Celso Suckow da Fonseca, \\ Petrópolis, RJ, Brasil \\ ${ }^{2}$ Instituto de Física, Universidade Federal do Rio de Janeiro, Rio de Janeiro, RJ, Brasil \\ ${ }^{3}$ Instituto Nacional de Ciência e Tecnologia de Nanodispositivos Semicondutores, Rio de Janeiro, RJ, Brasil \\ ${ }^{4}$ School of Physics, Trinity College, Dublin, Ireland \\ Recebido em 16/8/2012; Aceito em 9/1/2013; Publicado em 9/9/2013
}

\begin{abstract}
A maioria dos professores de física que leciona mecânica em todos os níveis de ensino faz uso dos tradicionais bloquinhos para ensinar as leis da estática e da dinâmica. Movimentos mais complexos como os do corpo humano em saltos, chutes ou arremessos são deixados de lado nessa análise. Propomos aqui uma maneira simplificada de analisar esses movimentos à luz dos conceitos básicos ensinados nos cursos de mecânica tradicionais, em especial o de centro de massa. Nessa abordagem, começamos com o estudo das partículas, passamos aos corpos rígidos (onde se incluem os bloquinhos) e depois para os movimentos básicos realizados pelo corpo humano em alguns esportes. Dessa forma, esperamos que o estudo da mecânica se torne mais prazeroso e contextualizado, fato que temos constatado ao longo de cursos ministrados e palestras oferecidas. Dada a extensão do tema, preferimos dividir o assunto em temas. Neste primeiro artigo, esclarecemos as bases teóricas das análises e tratamos, especificamente, dos saltos em alguns esportes coletivos.
\end{abstract}

Palavras-chave: ensino de física, mecânica, física no esporte, centro de massa.

Most teachers of physics who teach mechanics at all levels of education make use of the traditional blocks to teach the laws of statics and dynamics. More complex movements like the ones of human body in jumps, kicks or throws are left out of this analysis. We propose a simplified way to analyze these movements through some basic concepts taught in traditional mechanics courses, especially the center of mass. In this approach, we begin with the study of particles, proceed to rigid bodies (which include the blocks) and then to the basic movements of the human body in some sports. Thus, we expect that the study of mechanics becomes more pleasurable and contextualized, as we have seen in lectures and courses. Given the breadth of the subject, we prefer to divide the article into topics. In this first article, we clarify the theoretical analysis and treat jumps in some collective sports.

Keywords: physics teaching, mechanics, physics in the sport, center of mass.

\section{Introdução}

As leis básicas de todos os movimentos são o tema de uma das mais antigas e conhecidas subdivisões da física - a mecânica. Saber que se pode prever o que vai acontecer depois do instante inicial do movimento é algo extremamente fabuloso e encanta a todos aqueles que entram em contato com o estudo mais detalhado dessa área do conhecimento. Já no século XVIII, o fascínio sobre o tema levou a especulação sobre o conhecimento

\footnotetext{
${ }^{1}$ E-mail: danielmicha@hotmail.com.

do futuro. Pierre Simon (1749-1827), o marquês de Laplace, indagou sobre o assunto [1]:

Nós podemos tomar o estado presente do universo como o efeito do seu passado e a causa do seu futuro. Um intelecto que, em dado momento, conhecesse todas as forças que dirigem a natureza e todas as posições de todos os itens dos quais a natureza é composta, se este intelecto (demônio de 
Laplace) também fosse vasto o suficiente para analisar essas informações, compreenderia numa única fórmula os movimentos dos maiores corpos do universo e os do menor átomo; para tal intelecto nada seria incerto e o futuro, assim como o passado, seria presente perante seus olhos

Algumas teorias metafísicas e pseudocientíficas utilizam esses conceitos de passado, presente e futuro como base para suas predições. A astrologia é uma das vertentes que, sem embasamento científico, afirma que a posição dos astros no momento do nascimento de uma pessoa influencia sua história de vida e personalidade.

Fora as especulações, o triunfo da mecânica se deve exatamente ao determinismo. Isso se torna evidente em qualquer tipo de movimento, desde a previsão do tempo de viagem de uma bolinha jogada para cima até a análise do passo de dança mais complicado. Porém, para tal são necessárias informações sobre as condições iniciais e as interações físicas presentes no problema, assim como já dizia Pierre de Laplace. Apesar do enorme espectro de movimentos existentes na natureza e em nosso cotidiano, é o tradicional e insosso bloquinho que aparece nas lousas das salas de aula e permeia todo o período letivo de ensino de mecânica em todo o mundo, salvo raras exceções. Nesse artigo, propomos uma maneira mais instigante e prazerosa de tratar do tema mecânica: começando com o estudo dos movimentos de uma partícula, evoluindo para os corpos rígidos - e pelos próprios bloquinhos - e finalizando com a análise de movimentos complexos, através de simplificações e aproximações. O esporte é o enfoque principal nessa última etapa. Além de atraente e fascinante para qualquer público, o tema é perfeito para acompanhar esse estudo [2-6], haja vista a enorme diversidade e complexidade dos movimentos efetuados pelos atletas das diversas modalidades dessa atividade.

\section{Conceitos básicos de mecânica}

Através de um pequeno conjunto de equações, Isaac Newton (1643-1727) conseguiu resumir as leis básicas do movimento de qualquer partícula material, conhecidas como leis de Newton [7]. A lei de inércia, a relação fundamental da dinâmica e a lei de ação e reação são as premissas básicas ${ }^{\boldsymbol{\square}}$ para o início de qualquer análise de movimento. Compreendê-las e adquirir habilidade na resolução de problemas utilizando essas ferramentas é essencial na formação de qualquer estudante.

\subsection{Mecânica da partícula, bloquinhos e cen- tro de massa (CM): o estudo das transla- ções}

Apesar de as leis de Newton só se aplicarem às partículas materiais, o estudo da dinâmica, geralmente, se inicia com os famosos bloquinhos. Há um motivo lógico, mesmo que implícito, por trás dessa escolha: estudar o movimento de uma partícula material arbitrária é algo muito abstrato para os iniciantes em mecânica. Dessa forma, a introdução de objetos um pouco mais complexos - familiares no cotidiano dos alunos - se torna necessário. Essa é uma justificativa sensata para o uso dos bloquinhos. Mas, analisá-lo através das leis de Newton diretamente é um processo sutil. A escolha dos casos e situações deve ser cuidadosa: não pode haver qualquer tipo de rolamento, rotação em torno de qualquer eixo, movimentos internos, etc. Respeitadas essas condições, o bloquinho como um todo pode ser substituído por um ponto e a análise de seu movimento se torna muito mais simples. Esse ponto especial é denominado de centro de massa ${ }^{\mathbf{B}}$ (Fig. 1). Assim, através da evolução dos conceitos e exemplos demonstrados em sala de aula consegue-se atingir o objetivo principal dessa parte do curso: introduzir as leis de Newton na análise de movimentos simples.

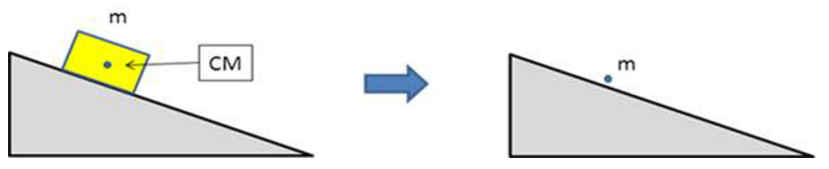

Figura 1 - A substituição do bloquinho de massa $m$ por um ponto material de mesma massa é, em certas condições, equivalente do ponto de vista mecânico.

O passo subsequente é a análise dos movimentos relativos. Apresenta-se, nesse momento, a dinâmica do conjunto de partículas, o conceito de centro de massa (CM) e de movimento relativo. O fato de o movimento do CM não ser alterado por forças e movimentos internos é intrigante e pouco intuitivo (Quadro 1). Porém, a absorção desse conteúdo é de extrema importância para a compreensão de movimentos mais complexos. Alguns casos, apresentados na Fig. 2, ilustram bem esse conceito. Na Fig. 2a, vê-se o caso clássico de um artefato explosivo, detonado no meio da trajetória de um lançamento oblíquo, manter a trajetória de seu CM, apesar das partes seguirem outras trajetórias após a explosão. Na Fig. 2b, vê-se um cilindro lançado obliquamente manter o movimento parabólico de seu CM mesmo girando em torno de um eixo que passa pelo mesmo.

\footnotetext{
${ }^{2}$ Outras formulações da mecânica, como a Lagrangeana, a Hamiltoneana e outras, também possibilitam a análise do movimento. Consideramos aqui a situação de um curso introdutório de mecânica.

${ }^{3}$ Sem esse esclarecimento e a definição de centro de massa, geralmente, feita a posteriori, o estudante pode acabar generalizando as leis de Newton para qualquer corpo rígido material.
} 
(a)

a)

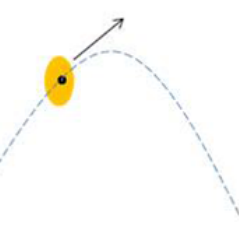

$3^{t_{1}}$
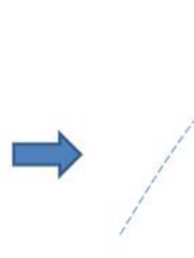

O $\uparrow$

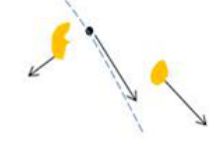

$\int^{t_{2}}$ (b)

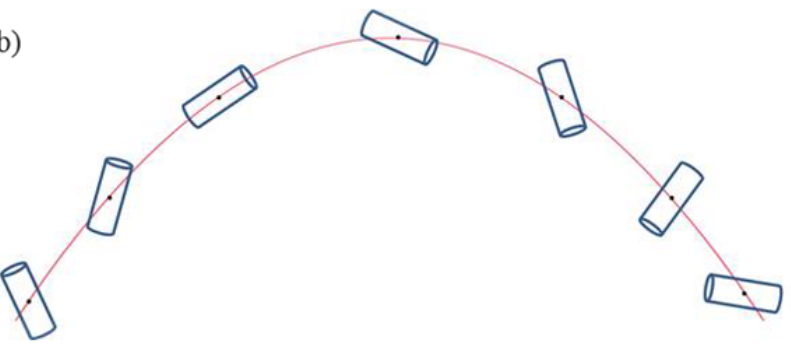

Figura 2 - Ilustrações de que forças e movimento relativos não alteram o movimento do CM (ponto preto). a: um artefato explosivo é lançado obliquamente e segue um movimento parabólico desde o início do lançamento. Em dado instante, ao explodir, os pedaços seguem trajetórias tais que o CM continue em seu movimento anterior. b: um cilindro lançado obliquamente gira em torno de um eixo que passa pelo seu CM, que mantem seu movimento parabólico.

\section{Translações e centro de massa $(\mathrm{CM})$}

A análise do movimento de translação para um conjunto de partículas é facilitada com a introdução dos conceitos de CM e das posições relativas das partes a esse. O CM de um grupo de $N$ partículas ou corpo rígido é um ponto ( $\mathbf{r}_{C M}$ ) definido como a média das posições das partículas $\left(\mathbf{r}_{i}\right)$ ponderada pelas massas das mesmas $\left(m_{i}\right)$. As posições relativas das partículas $\left(\mathbf{R}_{i}\right)$ ao CM são suas posições contadas a partir do CM. As definições destas duas grandezas são apresentadas na Eq. (1)

$$
\vec{r}_{C M}=\frac{\sum_{i=1}^{N} m_{i} \vec{r}_{i}}{\sum_{i=1}^{N} m_{i}}=\frac{\sum_{i=1}^{N} m_{i} \vec{r}_{i}}{M}, \quad \vec{R}_{i}=\vec{r}_{i}-\vec{r}_{C M}
$$

Para definir o momento linear do CM $\left(\mathbf{P}_{C M}\right)$, devemos definir sua velocidade (Eq. (2)).

$$
\vec{V}_{C M}=\frac{d \vec{r}_{C M}}{d t}=\frac{d}{d t} \sum_{i=1}^{N} \frac{m_{i} \vec{r}_{i}}{M}=\frac{1}{M} \sum_{i=1}^{N} \frac{d\left(m_{i} \vec{r}_{i}\right)}{d t}=\frac{1}{M} \sum_{i=1}^{N} \vec{p}_{i} .
$$

Com isso

$$
\vec{P}_{C M}=M \vec{V}_{C M}=\sum_{i=1}^{N} \vec{p}_{i}=\vec{p}_{\text {Total }} .
$$

O momento linear do CM é o momento linear total do sistema, como demonstrado na Eq. (3). A $2^{\text {a }}$ lei de Newton para uma partícula $i$ dentro de um conjunto de partículas é apresentada na Eq. (4).

$$
\vec{F}_{R_{i}}=\vec{F}_{i}^{E X T}+\sum_{j=1}^{N} \vec{F}_{i(j)}=\frac{d \vec{p}_{i}}{d t}
$$

onde no primeiro termo, $\mathbf{F}_{i}^{E X T}$ é o somatório das forças externas que atuam na partícula $i$, no segundo termo $\mathbf{F}_{i(j)}$ é a força da partícula $j$ sobre a partícula $i$ e o somatório considera as interações internas de todas as partículas e o último termo é a derivada temporal do momento linear da partícula $i$. Se somarmos a Eq. (4) para todas as partículas, ficamos com a Eq. (5).

$$
\sum_{i=1}^{N} \vec{F}_{R_{i}}=\sum_{i=1}^{N} \vec{F}_{i}^{E X T}+\sum_{i=1}^{N} \sum_{j=1}^{N} \vec{F}_{i(j)}=\sum_{i=1}^{N} \frac{d \vec{p}_{i}}{d t}
$$

Porém, da $3^{\text {a }}$ lei de Newton (Eq. (6)), sabemos que

$$
\vec{F}_{i(j)}=-\vec{F}_{j(i)}
$$

ou seja, a força que a partícula $i$ faz na partícula $j$ e reação a que a $j$ faz na $i$, o que faz o segundo termo da Eq. (5) se anular. Com isso, e derivando a Eq. (3),

$$
\vec{F}_{R E S}^{E X T}=\frac{d}{d t} \sum_{i=1}^{N} \vec{p}_{i}=\frac{d \vec{P}_{C M}}{d t},
$$

onde $\mathbf{F}_{R E S}^{E X T}$ é a força externa resultante no conjunto de partículas.

A Eq. (7) é a segunda lei de Newton para o conjunto de partículas, descrito a partir de seu CM. Essa equação nos diz que o movimento do CM não é alterado por força internas ao sistema, ou seja, qualquer movimento interno deve ser compensado por outro, afim de não violar essa lei.

Quadro 1: Análise teórica do movimento de translação do CM segundo as leis de Newton para um conjunto de partículas. 


\subsection{Mecânica dos corpos rígidos: iniciando o estudo das rotações}

Após a etapa anterior, inicia-se a o estudo dos movimentos de corpos rígidos, que são definidos como um conjunto de partículas que obedecem a certas restrições, tal como a manutenção da forma em um corpo sólido. Dessa forma, as translações dos corpos rígidos podem ser estudadas da mesma maneira que o conjunto de partículas, como já esclarecido na seção 2. O tópico discutido em seguida nos cursos de mecânica costuma ser a dinâmica das rotações, outro tipo de movimento fundamental observado em nosso cotidiano. Para isso, é necessário trabalhar com corpos rígidos, capazes de girar em torno de algum eixo e, por isso, precisamos definir grandezas como momento de inércia, torque, momento angular, etc.

As equações que definem as regras do movimento para as rotações são bem parecidas com as das translações. Similar a lei fundamental da dinâmica das translações - forças são responsáveis por alterar o momento linear de um corpo -, há uma para rotações, onde, agora, são os torques as quantidades capazes de alterar o momento angular de um corpo. Outra analogia surge da análise do conjunto de partículas, ou propriamente os corpos rígidos, onde apenas os torques externos são responsáveis por alterar o momento angular total do conjunto, não tendo os torques internos qualquer efeito sobre este (Quadro 2).

\section{Rotações e centro de massa (CM)}

A análise do movimento de rotação para um conjunto de partículas e para um corpo rígido pode ser simplificado com a introdução do conceito de CM, analogamente ao que fizemos na análise das translações (Quadro 1). Para uma partícula $i$ dentro de um conjunto com $\mathrm{N}$ partículas, o torque, em relação ao $\mathrm{CM}$, sentido devido à força realizada pela partícula $j$ é definido na Eq. (8). A notação do Quadro 1 é mantida.

$$
\vec{\tau}_{i(j)}=\vec{R}_{i} \times \vec{F}_{i(j)} .
$$

A segunda lei de Newton para as rotações da partícula $i$ é apresentada na Eq. (9).

$$
\vec{\tau}_{R_{i}}=\vec{\tau}_{i}^{E X T}+\sum_{j=1}^{N} \vec{\tau}_{i(j)}=\frac{d \vec{L}_{i}}{d t},
$$

onde o primeiro termo, $\mathbf{t}_{i}^{E X T}$, é a soma dos torques externos que atuam na partícula $i$, o segundo termo é o somatório de todos os torques internos sobre a partícula $i$ e o último termo é a derivada temporal do momento angular da partícula $i$. Se somarmos a Eq. (9) para todas as $N$ partículas, ficamos com a Eq. (10).

$$
\sum_{i=1}^{N} \vec{\tau}_{R_{i}}=\sum_{i=1}^{N} \vec{\tau}_{i}^{E X T}+\sum_{i=1}^{N} \sum_{j=1}^{N} \vec{\tau}_{i(j)}=\sum_{i=1}^{N} \frac{d \vec{L}_{i}}{d t}
$$

Usando propriedades vetoriais e a $3^{\mathrm{a}}$ lei de Newton

$$
\begin{aligned}
\vec{\tau}_{i(j)}=\vec{R}_{i} \times \vec{F}_{j(i)}= & \left(\vec{r}_{i(j)}+\vec{R}_{j}\right) \times \vec{F}_{j(i)}= \\
& -\vec{R}_{j} \times \vec{F}_{i(j)}=-\vec{\tau}_{j(i)}
\end{aligned}
$$

A Eq. (11) mostra que o torque que a partícula $i$ sente devido à força da partícula $j$ tem mesma direção e sentido contrário ao torque da força que a $i$ faz na $j$. Essa igualdade só é válida nos casos em que as forças que as partículas fazem umas nas outras estão na mesma direção da linha que as une. Com isso, o segundo termo na Eq. (10) é anulado, resultando na Eq. (12).

$$
\vec{\tau}_{R E S}^{E X T}=\sum_{i=1}^{N} \vec{\tau}_{R_{i}}=\frac{d}{d t} \sum_{i} \vec{L}_{i}=\frac{d \vec{L}_{C M}}{d t} .
$$

A Eq. (12) é a versão análoga para as rotações da segunda lei de Newton para as translações de um conjunto de partículas e de corpos rígidos descritos a partir de seu CM (Eq. (7) do Quadro 1). Essa equação mostra que a rotação do CM não é alterada por torques internos ao sistema, que, dessa forma, devem ser compensados por outros, afim de não violar essa lei.

Quadro 2: Análise teórica do movimento do CM nas rotações segundo as leis de Newton para um conjunto de partículas ou corpo rígido.

\section{Análise de movimentos do corpo hu- mano: os saltos nos esportes}

Todos os movimentos na natureza são compostos por translações e rotações. Com o corpo humano não é diferente. Nosso corpo é um conjunto de 206 ossos e 639 músculos (Fig. 3). Até o movimento aparentemente mais simples como a caminhada, para aqueles que não têm algum tipo de deficiência motora, é uma alternância entre estabilidade e desequilíbrio. Analisar qualquer um desses movimentos levando em consi- deração todas as partes envolvidas seria algo extremamente complexo. Porém, existe um caminho mais simples para avaliar esses movimentos: a análise do CM. Nessa série de artigos, nos comprometemos a fazer essa análise, começando por este, particularmente, para o caso dos saltos em alguns esportes coletivos.

\subsection{Avaliação do CM em situações de equilí- brio}

Comecemos nosso estudo pela análise da posição do CM de um corpo humano para algumas situações de 
equilíbrio. Lembramos que o CM de um corpo é um ponto, que não está necessariamente situado no próprio, definido pela média de distribuição espacial da massa do mesmo (Quadro 1). Para uma pessoa em pé, podemos considerar que o CM está situado, aproximadamente, no seu umbigo (Fig. 4a). Quando essa pessoa levanta um dos braços, o CM sobe um pouco (Fig. 4b), pois a massa se apresenta deslocada nesse sentido. Ao levantar o segundo braço, há mais elevação desse ponto (Fig. 4c). A alteração da posição do CM também ocorre a partir de posições mais complexas, como exemplificado nas Figs. 4d, 4e e 4f, que, inclusive, exemplifica o fato citado de o CM poder estar fora do corpo em estudo. (a)

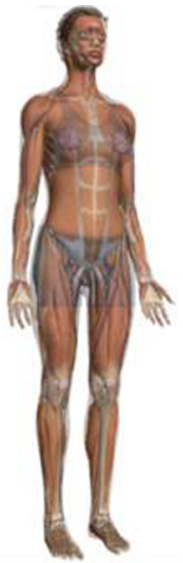

(b)

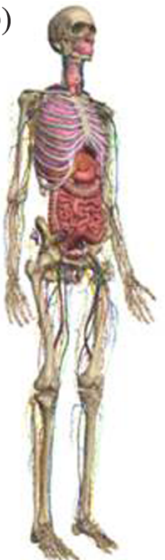

Figura 3 - Corpo humano. a. Estrutura muscular. b. Estrutura óssea, orgânica e nervosa (a)

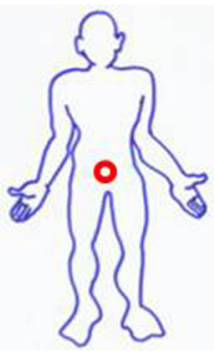

(b)

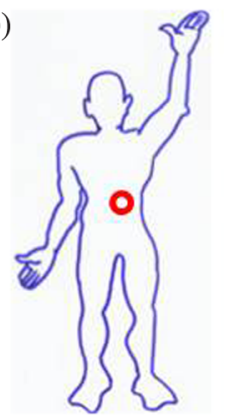

(c)

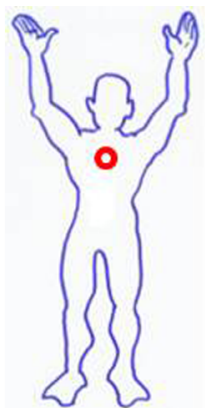

(d)

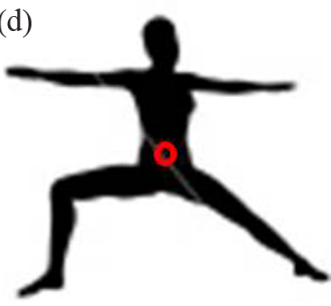

(e)

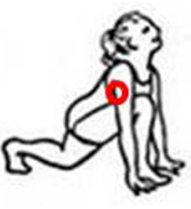

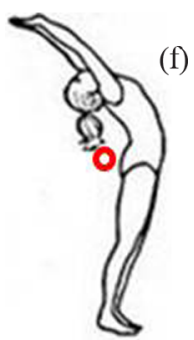

Figura 4 - Diversos arranjos corporais do corpo humano em situações de equilíbrio e a representação do CM (círculo vermelho) em cada um deles.

\subsection{Análise de saltos simples em esportes co- letivos}

Uma vez que discutimos a alteração na posição do CM mediante alguns arranjos corporais em situações de equilíbrio (Fig. 4), podemos partir para a análise dos saltos utilizados em alguns esportes coletivos. Para tal, consideraremos que os atletas, que concorrem a algum objetivo utilizando o salto, tem a mesma altura e impulsão inicial.

\subsubsection{Basquetebol}

O basquetebol é um esporte onde a altura física dos atletas é um fator determinante para que obtenham sucesso. Como o objetivo deste jogo é acumular pontos, fazendo a bola passar dentro de uma cesta a 3,05 $\mathrm{m}$ do solo, esse atributo é facilmente justificado. Porém, para chegar mais próximo e facilitar o objetivo, torna-se necessário que os atletas saltem. Nas subseções abaixo, serão discutidas maneiras de melhor aproveitar o salto com técnicas bastante simples.

\subsubsection{O salto vertical no basquetebol}

O salto vertical é um movimento muito utilizado no basquetebol. Na bola ao alto, no rebote, no arremesso e em diversas outras situações, os atletas necessitam sair do chão para alcançar a bola ou angariar certa vantagem frente aos atletas adversários. Mas, qual é o arranjo de corpo que o atleta deve escolher para alcançar tal objetivo? Para responder a essa pergunta, deve-se lembrar dos resultados obtidos nos Quadros 1 e 2. Uma vez que o atleta saiu do chão a partir de sua impulsão inicial, o movimento do CM não pode ser alterado por movimentos feitos por ele mesmo durante seu tempo no ar, pois isso configura um movimento interno. Porém, ele pode rearranjar seu corpo para que alguns pontos do mesmo alcancem pontos mais altos. Vamos organizar os bonecos da Fig. 4 de uma maneira diferente para tentar visualizar esse processo.

Na Fig. 5, os bonecos estão com o CM na mesma altura, considerada a máxima atingida após certa impulsão inicial. A parte do corpo que atinge uma altura maior é diferente nas três situações. Para os casos estudados nessa seção, os saltos verticais no basquetebol, chegamos a conclusão que o segundo arranjo na Fig. 5 é o mais indicado, com a elevação de um dos braços e o abaixamento do outro, pois faz com que o atleta tenha uma de suas mãos atingindo o ponto mais alto ou a bola. A Fig. 6 mostra algumas fotografias tiradas em jogos de basquetebol, onde os atletas lançam mão desse artifício para alcançar seus objetivos, provavelmente, motivados pela percepção do sucesso em seus treinos.

\subsubsection{O salto obliquo no basquetebol: hangtime}

Um dos efeitos mais bonitos e discutidos no basquetebol é o hangtime. Em inglês, essa expressão significa tempo de suspensão e, nesse esporte, é atribuida ao 
tempo prolongado de vôo de um atleta após um salto com a bola, geralmente, em uma enterrada (Fig. 7). Muitos dizem que o atleta voa e se mantem no ar flutuando na horizontal, desafiando a lei da gravidade. Mas, será isso possível?

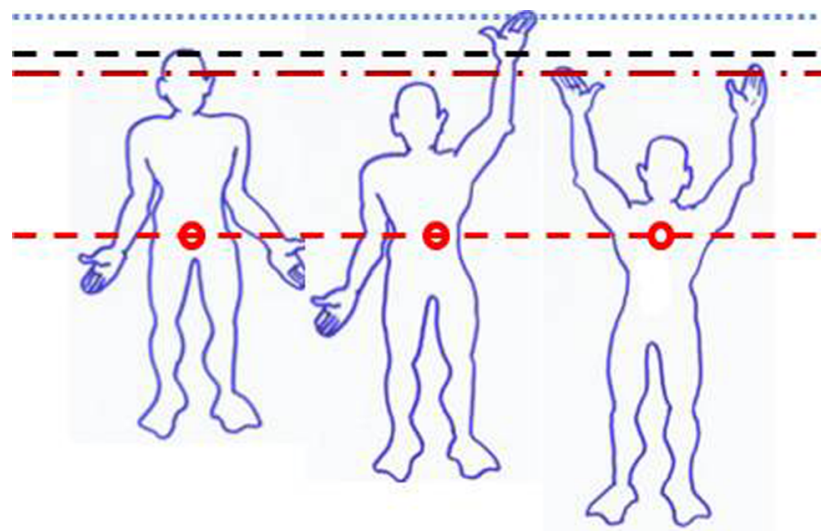

Figura 5 - Comparação das alturas atingidas em um salto a partir da mesma impulsão inicial e, consequentemente, mesma altura final do CM.
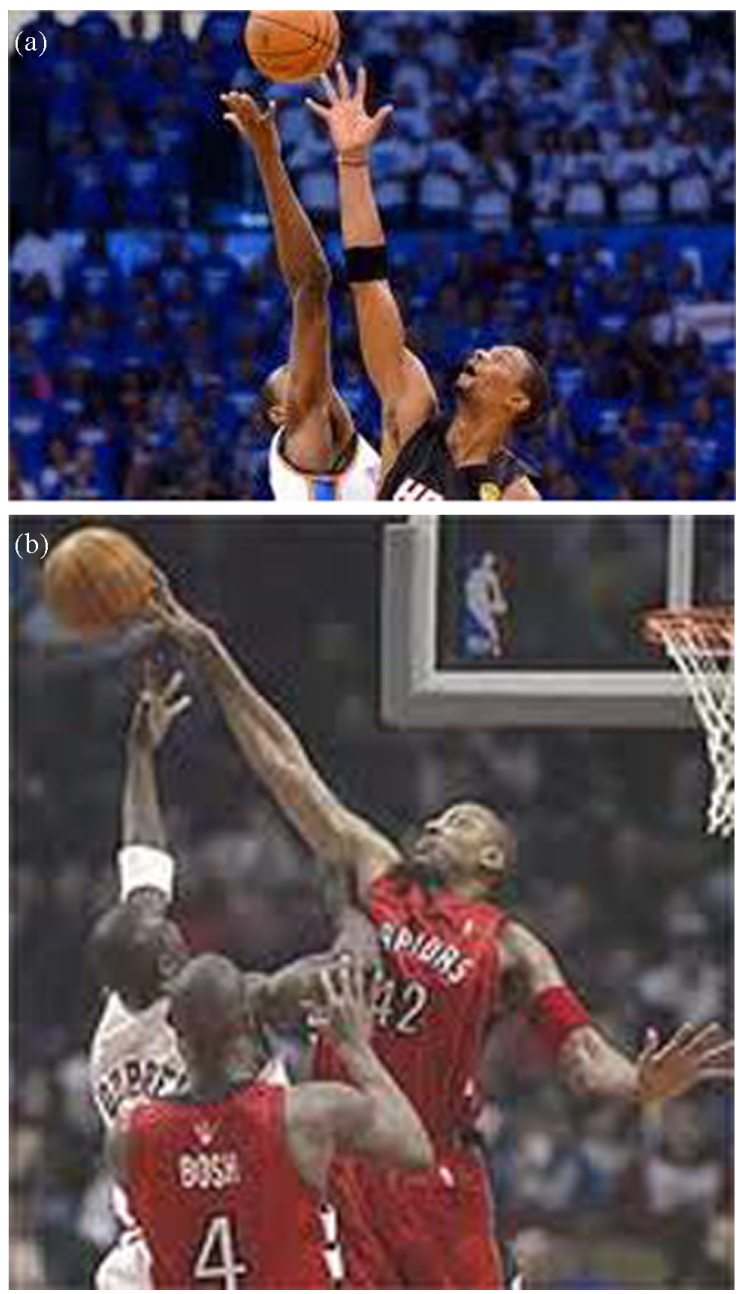

Figura 6 - Fotografias de disputas de bola em jogos de basquetebol da liga americana - NBA. Pode-se perceber que os atletas arranjam seus corpos de maneira a fazer com que uma de suas mãos atinja a bola antes dos adversários.

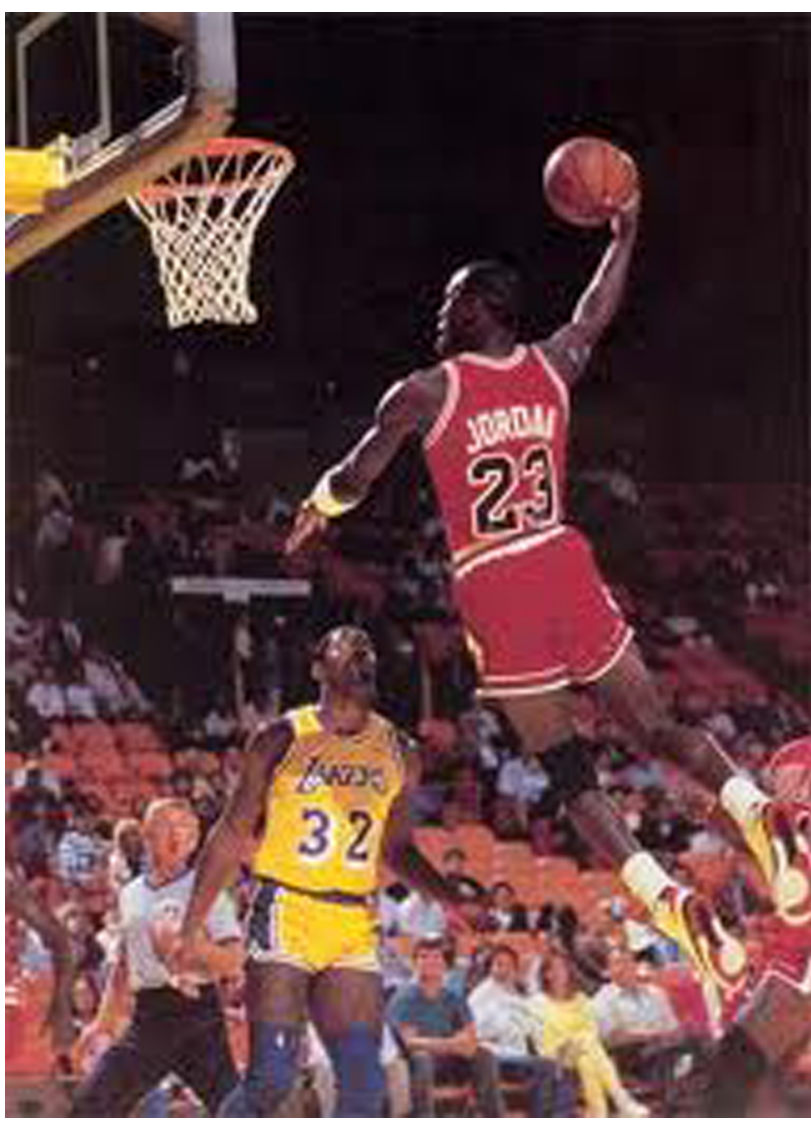

Figura 7 - Michael Jordan executando um hangtime prolongado em uma enterrada, jogada onde se tem a impressão que o atleta flutua no ar.

Bom, sabemos que leis são para serem cumpridas e, no caso das da física, isso se torna uma obrigação imposta pela natureza. Seguindo os resultados dos Quadros 1 e 2, garantimos que, após o salto, o CM tem que se manter em sua trajetória original. Nesse caso, como é um salto obliquo, a forma parabólica da trajetória tem de ser respeitada. Os atletas conseguem produzir o efeito de hangtime prolongado, rearranjando seus corpos durante o salto, como pode ser acompanhado na Fig. 8. Ao sair do solo, durante a propulsão, o atleta mantém seus braços abaixados. Após atingir uma certa altura, ele começa a elevar seus membros superiores em relação ao resto de seu corpo. Ao chegar na altura máxima do movimento do CM, o atleta eleva mais um dos braços (linha vermelha), para fazer a bola alcançar uma altura maior e assim permanece até a enterrada. Durante grande parte do movimento, por conta dos diferentes arranjos de seu corpo, a cabeça do atleta permanece em um movimento puramente horizontal (linha verde), o que fascina e confunde o observador que não se atenta ao fato de que seu CM (linha amarela) percorreu o mesmo movimento parabólico de "sempre". Além da performance artística desse salto, ele se torna estratégico para a meta, pois faz com que a bola esteja boa parte do tempo em uma altura muito elevada e dificulta o marcador de realizar uma intervenção (toco). 


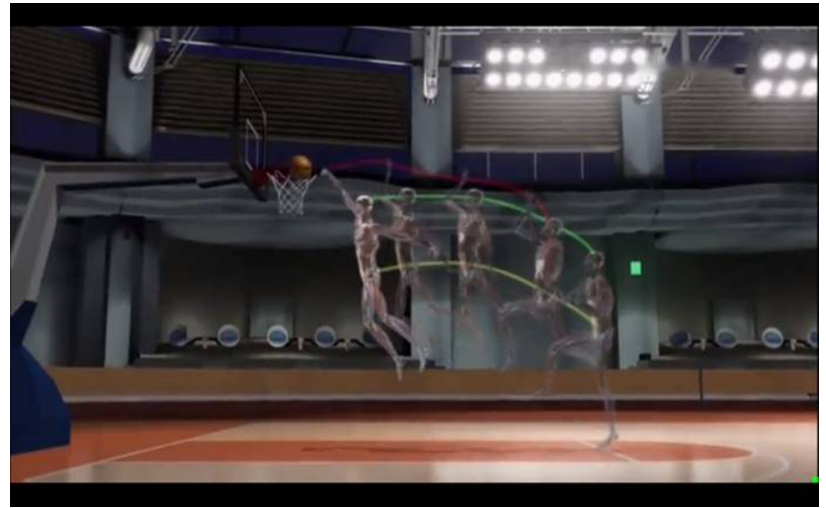

Figura 8 - nálise mecânica $(\mathrm{CM})$ do hangtime prolongado, movimento plástico executado por alguns atletas para "enterrar" a bola na cesta e marcar pontos no basquetebol.

\subsubsection{Voleibol}

O voleibol é outro esporte onde a altura física dos atletas é importante para o objetivo final. Nesse esporte, vence a equipe que fizer mais pontos, contabilizados quando a bola, ao passar por cima de uma rede, entra em contato com o solo adversário. Essa rede fica localizada no centro da quadra e tem uma altura de 2,43 $\mathrm{m}$, em competições masculinas adultas, e 2,24 m, em competições femininas adultas. Mais uma vez, o atributo altura e o fundamento salto se justificam frente ao objetivo final.

\subsubsection{O salto vertical no voleibol}

Estatisticamente, o maior número de pontos em um jogo de voleibol ocorre em dois movimentos principais: o ataque de cortada (depois da linha dos 3 metros) e a defesa de bloqueio, ambos realizados rente à rede. Nestes dois movimentos são utilizados saltos verticais (em alguns casos, levemente oblíquos) com o objetivo de fazer a bola passar ao campo adversário, no caso do ataque, ou impedir o mesmo, no caso da defesa. Para isso, torna-se fundamental para o atacante vencer a altura do defensor adversário. No caso do defensor, ele deve saltar para ocupar o maior espaço aéreo possível, além, é claro, de estar alto o suficiente para que a bola não passe por cima de seu corpo.

No caso da cortada, o jogador atacante deve fazer com que sua mão chegue até a bola, levantada pelo "levantador" em uma altura considerável, "cortandoa" (batendo com força) de cima para baixo em direção ao solo do campo adversário. Como um dos objetivos é vencer a altura dos defensores bloqueadores, ele utiliza o segundo arranjo corporal da Fig. 5, elevando um dos braços e abaixando o outro, fazendo com que uma de suas mãos alcance o ponto mais alto.

No caso do bloqueio, o jogador defensor deve impedir que a bola "cortada" pelo atacante chegue a seu campo. Como o atacante "corta" a bola de cima para baixo e ele faz esse movimento a certa distância da rede, dentro de seu campo de origem, a mesma chega rente à rede a uma altura considerada média. Por conta disso, não é necessário que o defensor salte mais alto ou em altura igual ao atacante, possibilitando que atinja o objetivo do bloqueio com o terceiro arranjo corporal da Fig. 5, isto é, levantando os dois braços.

A Fig. 9 ilustra os movimentos descritos nos parágrafos anteriores. Pode-se perceber, através da fotografia, que o atacante (atleta de uniforme amarelo) projeta sua mão a uma altura maior que a das mãos do defensor (atleta de uniforme vermelho), que ocupa uma área espacial maior ao levantar suas duas mãos.

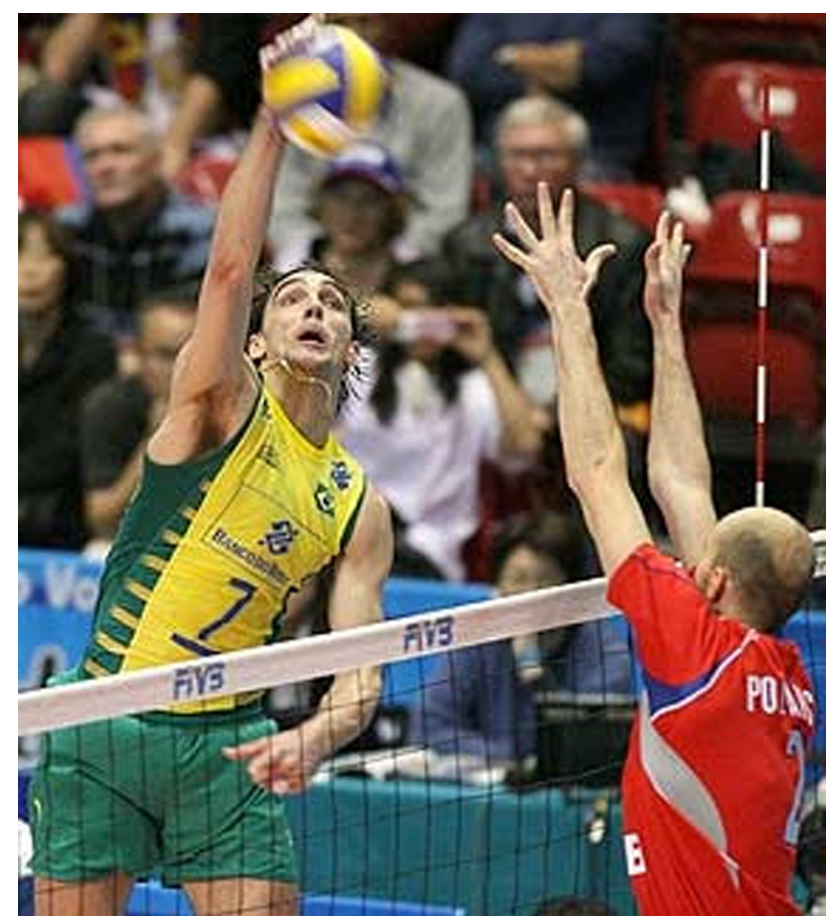

Figura 9 - Fotografia de um atacante da seleção brasileira de voleibol - uniforme amarelo - "cortando" a bola em direção ao outro lado da quadra, enquanto um defensor da seleção adversária tenta bloqueá-lo.

\subsubsection{O salto obliquo no voleibol}

O salto oblíquo no voleibol é outro recurso utilizado no ataque nos movimentos de "cortada" antes da linha dos 3 metros e de saque. Os jogadores que se encontram em posição de recepção ou defesa, atrás da linha que fica a 3 metros da rede, só podem atacar partindo, originalmente, dessa região. Esses atletas conseguem certa vantagem executando o salto oblíquo, de forma que iniciam seu movimento atrás da linha dos 3 metros (como dita a regra) e atingem a bola em uma posição mais afastada da rede. No movimento de saque, geralmente, os jogadores lançam a bola para frente e para cima e a golpeiam em seu ponto mais alto. Para alcançar a bola, que não se encontra mais na mesma posição horizontal, o atleta também deve realizar um salto oblíquo.

Para lograr êxito nos dois movimentos, o atleta que realiza a "cortada" da linha dos 3 metros ou o saque deve executar o segundo arranjo corporal da Fig. 5, 
elevando um dos braços e abaixando o outro, pois terá uma de suas mãos na maior altura possível neste tipo de salto e, com isso, terá uma maior chance de fazer a bola passar pelo bloqueio adversário, no caso do ataque, ou pela rede, no caso do saque.

Para conseguir maior probabilidade de marcar pontos em um ataque, outro atributo essencial nas jogadas é a velocidade com que a bola segue para o campo da equipe adversária. É possível obter maiores velocidades para a bola através da maior potência na "cortada" e, também, da maior transferência de momento linear do atleta para a mesma, fatos que não estão sendo considerados na discussão que envolve somente a análise do CM. O lançamento oblíquo da bola é um recurso interessante, pois faz com que a mesma já possua uma componente de seu momento linear na direção do movimento desejado (vetor laranja fino na Fig. 10). O salto oblíquo do atleta na direção do campo adversário faz com que, no momento do golpe na bola, seja transferido parte do momento linear inicial de seu corpo (vetor vermelho grosso na Fig. 10), conferindo à bola maior velocidade na direção desejada (vetor laranja grosso na Fig. 10).

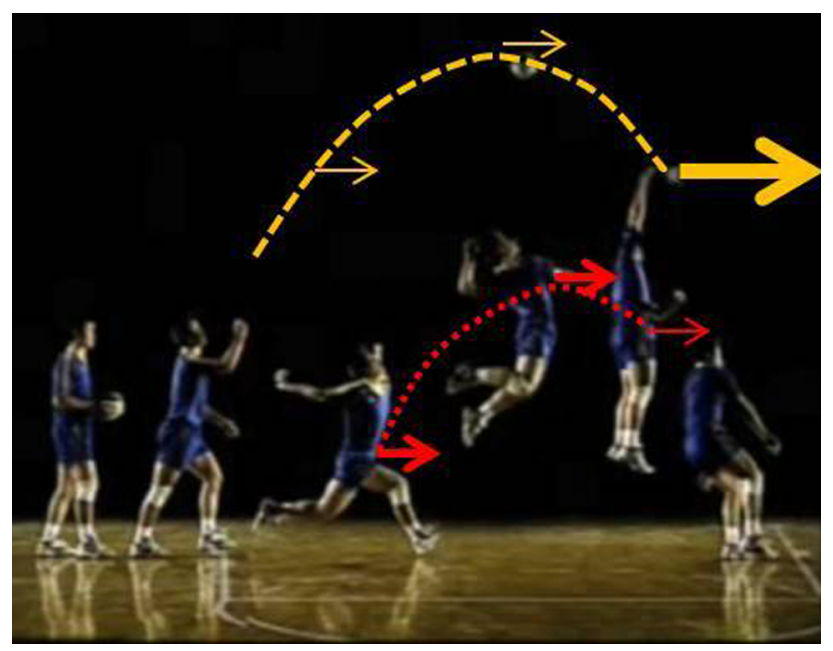

Figura 10 - Análise mecânica (CM) do movimento feito por um jogador de voleibol para realizar um saque.

\subsubsection{Futebol}

No futebol, a grande meta é o gol - unidade de pontuação. Ele pode ser conseguido a partir de qualquer movimento com a bola sem a utilização dos braços e das mãos como, por exemplo, chutes e cabeçadas. Ultimamente, no estilo de futebol atual, tem-se utilizado muito o recurso da bola parada (cobranças de falta e de escanteios) como jogada primordial para conseguir o objetivo de marcar os pontos. Nessas jogadas, a bola é lançada na área do goleiro pelo time atacante, que tenta tocar a bola com a cabeça para desviá-la em direção ao gol. No caso específico do ataque no futebol, diferentemente dos esportes anteriores, não é a mão a parte do corpo que deve alcançar a bola em seu ponto mais alto, mas, sim, a cabeça. Para concretizar esse objetivo, o atleta deve arranjar seu corpo de acordo com a primeira configuração da Fig. 5, ou seja, com os braços para baixo. Já o defensor goleiro, a quem é permitido colocar a mão na bola dentro de sua área, a estratégia mais eficaz é arranjar seu corpo como na segunda configuração da Fig. 5, com um dos braços levantados e outro abaixado.

A Fig. 11 é uma fotografia tirada em um jogo da seleção brasileira, onde podemos ver a disputa da bola entre um atacante (camisa amarela) e o goleiro da equipe adversária (camisa azul). Nesta, é possível visualizar os conceitos discutidos. A cabeça do atacante, claramente, está em uma altura maior do que a da cabeça do goleiro. Porém, como este pode utilizar as mãos, toma vantagem e consegue atingir a bola em um ponto mais alto. Note a semelhança entre as posições corporais e alturas alcançadas dos atletas mencionados e as imagens da Fig. 5.

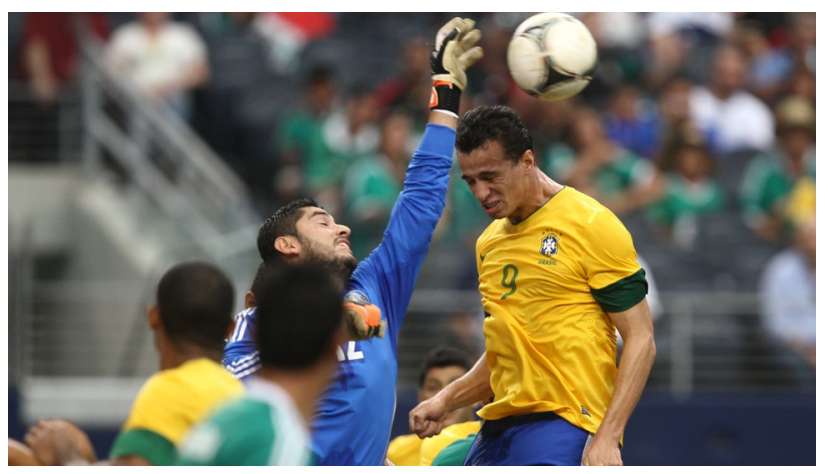

Figura 11 - Fotografia de uma disputa pela bola em um ataque de futebol. O atacante da seleção brasileira (jogador de uniforme amarelo) tenta alcançar a bola com a cabeça, mas é o goleiro do time adversário (jogador de uniforme azul) quem toca nela primeiro.

\section{Conclusão}

Neste artigo introdutório da série "física no esporte", demonstramos que é possível realizar a análise de movimentos complexos reduzindo-os a um problema mecânico mais simples. Utilizamos o conceito de centro de massa para substituir o grande número de variáveis existentes em movimentos do corpo humano. Desta forma, pudemos avaliar o melhor arranjo corporal em situações de saltos em alguns esportes, tais como o basquetebol, o voleibol e o futebol. Pela extensão do assunto, preferimos dividir essa publicação em diversos artigos, de modo que pudessem ficar mais proveitosos ao leitor. Gostaríamos de ressaltar a grande aceitação da abordagem do tema nas aulas e palestras que temos oferecido, fato que nos tem motivado a replicar e a publicar o trabalho. O tema é, por si só, extremamente atraente e tem um enorme potencial para ser utilizado na "sedução" dos iniciantes nos estudos da física e, em particular, da mecânica. 


\section{Referências}

[1] P.S. Laplace, Essai Philosophique sur les Probabilités (Courcier Imprimeur, Paris, 1814).

[2] C.E. Aguiar e G. Rubini, Revista Brasileira de Ensino de Física 26, 297 (2004).

[3] M.A.F. Gomes e E.J.R. Parteli, Revista Brasileira de Ensino de Física 23, 10 (2001).

[4] A.J.S. Filho, A. Chispino e J.L. Fernandes, Revista Brasileira de Ensino de Física 34, 2306 (2012).
[5] A.J.S. Filho, Física Aplicada ao Desporto: Um Estudo Interdisciplinar entre Física, Educação Física e Desporto. Dissertação de Mestrado, Centro Federal de Educação Tecnológica Celso Suckow da Fonseca, Rio de Janeiro, 2010.

[6] A.J.M. Miron, A Fúsica da Natação. Monografia de Licenciatura em Física, Universidade Federal do Rio de Janeiro, Rio de Janeiro, 2009.

[7] I. Newton, Newton's Principia: The Mathematical Principles of Natural Philosophy (London, 1687). 